1/10 Normal-Thiosulfatlösung einfiessen, deren Wirkungswerth gegen eine bekannte Menge Ferrioxyd festgestellt ist.

Die Flüssigkeit bleibt nun so lange stehen, bis sie vollständig farblos geworden ist, worauf man das überschüssige Thiosulfat mit $1 / 10$ Normaljodı̈ösung und Stärke bestimmt. Beträgt die Menge des Eisenoxyds bis zu $0,2 \xi$, so verläuft die Reaction schnell und gibt gute Resultate; es können auch bis $0,4 g$ Eisenoxyd in Arbeit genommen werden, wenn die oben erwähnten Verhältnisse der Acidität und Verdünnung der Lösung genau eingehalten werden.

Die Anwendung von Kupfersulfat, wie oudemans vorgeschlagen hat, oder von Natriumsalicylat nach $\mathrm{Hasw}$ ell scheint nicht nöthig und verursacht nur Störungen.

\title{
Ueber die titrimetrische Bestimmung des Quecksilbers durch
} Natriumthiosulfat in Mercurichlorid, Mercuronitrat und Mercurinitrat nach der Metbode von J. J. Sherer hat J. T. Norton jun. ${ }^{1}$ ) im Hinblick auf die offenbaren Schwierigkeiten, welche das Verfahren bietet, eingehende Versuche angestellt. Dieselben haben ergeben, dass das Verfahren bei der Bestimmung des Quecksilbers in der Form von Mercurichlorid genaue Resultate liefert, wenn man es unter genauer Beachtung der folgenden Versuchsbedingungen ausführt.

Man bringt die Mercurichloridlösung in einem Literkolben auf $100 \mathrm{cc}$, erwärmt auf $60^{\circ} \mathrm{C}$. und lässt eine ${ }^{1} / 20$ Normallösung von Natriumthiosulfat aus einer Bürette in die Lösung einfliessen, bis der zuerst weisse Niederschlag eine bräunliche Färbung annimmt. Hierauf verdünnt man die Lösung mit kaltem Wasser, fügt etwas Asbestfaser hinzu, damit sich der Niederschlag besser zusammenballt, und bringt das Ganze auf ein Filter. Als solches benutzt man am besten einen grossen, perforirten Platinconus, auf welchem eine Filterschicht von Asbest ausgebreitet ist. Der Platinconus wird mittelst einer Gummiverbindung in einen Glastrichter eingesetzt, dessen Röhre durch den Stopfen eines grossen Erlen m e y er'schen Kolbens mit seitlicher Ansatzröhre hindurchgeht. Nach sorgfältigem Auswaschen des Niederschlags wird das Filtrat auf ein bestimmtes Volumen verdünnt, mit 3 g Jodkalium versetzt and das überschüssige Thiosulfat mit Jodlösung zurückbestimmt. Die Dauer der Operation darf nicht über 15 Minuten hinausgehen. Ein Zusatz

1) Zeitschrift f. anorgan. Chemie $\mathbf{2 4}, 411$. 
von Salzsäure ist bei der Titration nicht nothwendig und kann nur die Ursache einer Fehlerquelle werden.

Bei Anwendung desselben Verfahrens zur Bestimmung des Quecksilbers, welches in Form von Mercuronitrat oder von Mercurinitrat vorhanden ist, konnte der Verfasser nicht $\mathrm{zu}$ brauchbaren Resultaten gelangen.

Zur Trennung und Bestimmung des Quecksilbers als Mercurooxalat. Nach den Angaben der Litteratur werden Lösungen von Mercurosalzen durch Oxalsäure, sowie die sauren und neutralen Oxalate der Alkalien gefällt, während in Mercurichloridlösungen weder durch Oxalsäure, noch durch die Doppeloxalate des Kaliums ein Niederschlag hervorgerufen wird. Auf Grund dieser Thatsachen hat C. A. Peters ${ }^{1}$ ) eine Bestimmungsmethode für das Quecksilber ausgearbeitet und zwar eine volumetrische Nethode, bei welcher die Oxalsäure titrimetrisch zu ermitteln ist, und eine gravimetrische Methode, bei welcher das gefällte Mercurooxalat direct zur Wägung gebracht wird.

Eine Lösung von Mercuronitrat, entsprechend 0,1-0,3 $g$ Quecksilber, wurde in der Kälte mit einer auf eine $1 / 10$ Normal-Kaliumpermanganatlösung eingestellten Lösung von Ammoniumoxalat gefällt, der Niederschlag wurde über Asbest abfiltrirt, ein- oder zweimal mit kaltem Wasser gewaschen und die überschüssige Oxalsäure im Filtrate mit Permanganatlösung zurückbestimmt. Die Bestimmung erfolgte entweder bei Gegenwart von Salzsäure und von Manganosalz bei $20-40^{\circ} \mathrm{C}$, oder unter Zusatz von Schwefelsäure in bekannter Weise. Die erhaltenen Resultate sind vollkommen genau.

Versuche, das abfiltrirte Mercurooxalat zu lösen und die Oxalsäure in der Lösung titrimetrisch zu bestimmen, führten nicht zu befriedigenden Ergebnissen.

Da Mercurooxalat in kalter, verdünnter Salpetersäure unlöslich ist, während sich Mercurioxalat darin mehr oder weniger leicht löst, versuchte der Verfasser festzustellen, ob und unter welchen Bedingungen sich mit Hülfe verdünnter Salpetersäure eine Trennung der Mercurosalze von kleinen Mengen Mercurisalzen ausführen lässt. Es ergab sich hierbei, dass aus einer Lösung, welche 2 bis $5 \%$ Salpetersäure von 1,15 specifischem Gewicht enthält, das Mercurosalz quantitativ als Oxalat von geringen Mengen von Mercurisalzen getrennt werden kann. Die

1) Zeitschrift f. anorgan. Chemie 24, 402.

Fresenius, Zeitschrift f. analyt. Chemie. XLI. Jahrgang. 9. Heft. 